\title{
Musculosidade e composição da perna de ovinos de diferentes genótipos e idades ao abate
}

\author{
Américo Garcia da Silva Sobrinho ${ }^{(1)}$, Roger Walter Purchas ${ }^{(2)}$, Isam Tawfik Kadim ${ }^{(3)}$ e Sandra Mari Yamamoto(1)
}

(1)Universidade Estadual Paulista, Fac. de Ciências Agrárias e Veterinárias, Via de Acesso Prof. Paulo Donato Castellane, CEP 14884-900 Jaboticabal, SP. E-mail: americo@fcav.unesp.br, yamamoto@fcav.unesp.br (2)Institute of Food, Nutrition and Human Health, Massey University, Private Bag 11222, Palmerston North, New Zealand. (3)College of Agricultural and Marine Sciences, Sultan Qaboos University, Al-Khod 123, Sultanate of Oman, Oman.

\begin{abstract}
Resumo - Foram avaliadas as características morfológicas da carcaça, musculosidade e composição tecidual da perna de cordeiros criados em regime de pasto, provenientes de ovelhas Romney, acasaladas com três raças paternas (Romney, East Friesian x (Finn x Texel) e Finn x Poll Dorset). Aos 150 e 300 dias de idade, os cordeiros foram abatidos em dois lotes, cada um com 15 animais de cada raça paterna, num total de 90 animais. O grupo oriundo de animais East Friesian x (Finn x Texel) apresentou maior quantidade de músculo na perna (1.975 g) e, em comparação ao grupo Romney, semelhante musculosidade da perna $(0,45)$ e maior relação músculo:osso $(7 \times 6,69)$. A musculosidade da perna nos animais descendentes de Finn x Poll Dorset foi menor $(0,44)$, quando comparada à dos demais grupos. Cordeiros abatidos mais tardiamente apresentaram carcaças mais longas e magras, provavelmente pelas condições adversas do verão e do outono, em que são típicas a menor taxa de crescimento e a qualidade inferior de forragem. O genótipo e a idade de abate influem nas características morfológicas da carcaça, no índice de musculosidade e de composição tecidual da perna dos cordeiros.
\end{abstract}

Termos para indexação: carcaça, cordeiros, morfologia.

\section{Muscularity and leg composition in lambs of different genotypes and ages at slaughter}

\begin{abstract}
Carcass morphologic characteristics, muscularity and leg tissue composition of pasture fed lambs (Limestone Downs farm, New Zealand) born to Romney ewes and sired by Romney, East Friesian x (Finn x Texel), and Finn $x$ Poll Dorset were evaluated for carcass composition and meat quality. Animals were slaughtered in two age groups (150 and 300 days), each group containing 15 animals of each sire breed, comprising a total of 90 animals. The East Friesian x (Finn x Texel) sired group presented the highest weight-adjusted percentage of leg muscle (1,975 g), and relatively to the Romney group, it had similar leg muscularity ( 0.45$)$, but higher muscle to bone ratio (7x6.69). Finn x Poll Dorset sired group presented less leg muscularity (0.44) than the other genotypes. Lambs slaughtered at the older age had longer and leaner carcasses at the same weight, probably because of summer-autumn adverse conditions, typically with slower pasture growth rates and herbage quality. Both genotype and slaughter age influence carcass morphologic characteristics, muscularity and leg tissue composition of lambs.
\end{abstract}

Index terms: carcass, lamb, morphology.

\section{Introdução}

O uso de cruzamentos terminais, nos empreendimentos de engorda de ovinos, pode incrementar a lucratividade, se a taxa de crescimento animal e o valor da carcaça forem aumentados. As raças com potencial para aumentar a lucratividade são aquelas com alto peso à maturidade e propensão genética à produção de carne magra, das quais a Texel é um bom exemplo (Clarke et al., 1984; Purchas, 1990). Contudo, os resultados des- ses cruzamentos mostram que os aumentos obtidos em peso vivo e de carcaça, assim como a melhora da conformação, nem sempre vêm acompanhados de carne de qualidade superior. Portanto, a utilização do peso como único parâmetro de qualidade da carcaça é inadequada, tendo-se de considerar fatores como a relação músculo:osso:gordura, a conformação e, principalmente, a idade do animal.

A musculosidade da carcaça é definida como a espessura de músculo em relação às dimensões do esque- 
leto, e a conformação da carcaça como a espessura de músculo e de gordura, em relação às dimensões do esqueleto (Deboer et al., 1974). Entretanto, apesar da clareza das definições, medidas objetivas da musculosidade são pouco relatadas, pelas dificuldades em se medir a profundidade média do músculo. Assim, a maioria dos trabalhos utiliza escores subjetivos (Kempster et al., 1981; Kirton et al., 1983).

A relação músculo:osso fornece o índice de musculatura de carcaça (Anous, 1989) e, quando alta, está associada à musculosidade superior (Dumont \& Pouliquen, 1988). Teoricamente, maior relação músculo:osso pode decorrer de ossos mais leves, ao invés de músculos mais pesados. Medidas de musculosidade podem, também, não diferir, mesmo quando há diferenças na quantidade de músculo, decorrentes das variações no comprimento de osso, por causa da idade, considerando-se uma mesma raça.

Dentre os propósitos do conceito de musculosidade, está a descrição do conteúdo de músculo da carcaça, em relação ao seu tamanho. O termo tamanho, nesse contexto, é função da dimensão do esqueleto. De acordo com Purchas et al. (1991), uma medida objetiva de musculosidade é a relação entre a profundidade média de um grupo de músculos, ao redor de um osso, e o comprimento desse osso. A profundidade média dos músculos foi indiretamente avaliada como a raiz quadrada do peso de um grupo de músculos, dividida pelo comprimento de um osso adjacente.

A conformação da carcaça, quase sempre avaliada visualmente e expressa por escores, adiciona uma dimensão diferente na predição da composição de carcaça. É necessária a atenção à gordura na carcaça, para que a conformação seja um dado útil e valioso na identificação de raças (Kempster et al., 1982). O peso e a conformação das carcaças são cada vez mais considerados na comercialização da carne ovina, como critério de avaliação do seu valor; as melhores são preferidas pelo consumidor e adquirem maiores preços em relação às deficientes (Osório et al., 1996).

A conformação visual da carcaça é definida como a avaliação da espessura de músculo e gordura, em relação ao tamanho do esqueleto (Butterfield, 1988, citado por Nsoso et al., 2000). Uma deficiência no uso do conceito de conformação visual é a correlação das medidas in vivo e na carcaça, que resultam em índices diferentes, dependendo da habilidade do avaliador e da região avaliada no corpo do animal (Kempster et al., 1982).
A vantagem da conformação, como indicativo de carcaça magra, parece ser atribuída à identificação de diferenças na relação músculo:osso. Apesar disso, Kempster et al. (1982), ao avaliar diferentes raças, reportaram que aquelas com melhor conformação não tiveram, necessariamente, maiores relações músculo:osso. Mais uma vez, a baixa correlação entre raças pode refletir-se em diferenças na estrutura óssea.

O trabalho teve como objetivo avaliar a conformação das carcaças, a musculosidade e a composição tecidual de pernas de cordeiros, de diferentes genótipos, abatidos aos 150 e 300 dias de idade.

\section{Material e Métodos}

Foram utilizados 90 cordeiros oriundos de partos simples, nascidos no inverno de 1998, na Fazenda Limestone Downs, situada na costa oeste da Ilha Norte, ao norte de Raglan, Nova Zelândia. Os cordeiros eram produtos de fêmeas Romney acasaladas com machos Romney (controle), East Friesian x (Finn x Texel) e Finn x Poll Dorset, perfazendo grupos de 30 fêmeas para cada raça paterna. Os cordeiros foram pré-selecionados, tomando-se como base o peso ao desmame (90 dias), tendo sido eliminados os $12 \%$ mais leves e os $12 \%$ mais pesados. Depois da pré-seleção, 90 cordeiros foram selecionados ao acaso, 30 para cada grupo de raça paterna. Os 90 animais foram divididos, também ao acaso, em dois lotes de abate de 45 animais, cada lote com 15 cordeiros de cada grupo paterno. Os ovinos pastaram, durante todo o experimento, em pastos com predominância de azevém (Lolium perenne L.) e trevo branco (Trifolium repens L.), cuja composição bromatológica está descrita na Tabela 1.

Os borregos do lote 1 (150 dias) e do lote 2 (300 dias) foram abatidos em dezembro de 1998 e em maio de 1999, respectivamente. Após jejum de sólidos por 16 horas,

Tabela 1. Composição bromatológica das forrageiras, em porcentagem de matéria seca.

\begin{tabular}{lrc}
\hline Fração & \multicolumn{2}{c}{ Forragem } \\
\cline { 2 - 3 } & Azevém & Trevo branco \\
\hline Proteína bruta & 14,20 & 21,70 \\
Extrato etéreo & 3,10 & 5,00 \\
Nutrientes digestíveis totais & 51,50 & 66,00 \\
Fibra em detergente neutro & 70,70 & 45,60 \\
Fibra em detergente ácido & 38,80 & 33,20 \\
Cálcio & 0,30 & 1,30 \\
Fósforo & 0,26 & 0,36 \\
\hline
\end{tabular}


os animais foram insensibilizados com pistola de dardo cativo, sangrados e esfolados, segundo procedimentos de um abatedouro comercial. Após esfola e evisceração, a carcaça foi separada das patas, nas articulações carpometacarpiana e tarso-metatarsiana.

Após o abate, o comprimento da carcaça foi medido em ambos os lados, desde o bordo lateral da articulação tarso-metatarsiana até a extremidade cranial do esterno, com uso de fita métrica. No mesmo dia, a conformação da carcaça foi avaliada, usando-se as classes de conformações S, E, U, R, O, P (Modelo..., 1994) (Figura 1).

As carcaças foram pesadas e divididas, longitudinalmente, depois de 24 horas em câmara fria a $4^{\circ} \mathrm{C}$. A perna, o lombo, as costelas com a paleta e o pescoço foram removidos de acordo com as especificações da The Meat Export Development Company of New Zealand, tendo-se realizado um corte entre a perna e a penúltima vértebra lombar, e outro entre a última e a penúltima vértebra torácica. Foi removida a extremidade distal do osso da tíbia, deixando-se o M. gastrocnemius solto. As pernas foram embaladas em sacos plásticos e congeladas para posteriores dissecações.

Os procedimentos de dissecação das pernas ovinas foram realizados segundo método de Brown \& Willians (1979). Antes de serem dissecadas, as pernas foram descongeladas a $10^{\circ} \mathrm{C}$ por 20 horas, dentro dos sacos plásticos; em seguida, foram preparadas para dissecação, retirando-se qualquer tecido extra, gordura associada, canais de gordura, outros tecidos moles mediais ao osso pélvico e todas as vértebras caudais, exceto as duas primeiras. As pernas limpas foram, então, pesadas.

Na dissecação, foram separados os seguintes grupos de tecidos: gordura subcutânea ou gordura externa, localizada abaixo da pele; gordura intermuscular, abaixo da fáscia profunda, entre os músculos; músculos; ossos; tendões; glândulas; nervos e vasos sangüíneos. Os músculos bíceps femoral, semitendinoso, adutor, semimembranoso e quadríceps femoral foram removidos e pesados individualmente.

O índice de musculosidade da perna foi calculado pela fórmula descrita por Purchas et al. (1991): índice de musculosidade $=[(\mathrm{PM} 5 / \mathrm{CF}) / \mathrm{CF}]^{0,5}$, em que PM5 é o peso (g) dos cinco músculos que recobrem o fêmur (bíceps femoral, semitendinoso, adutor, semimembranoso e quadríceps femoral; e CF é o comprimento $(\mathrm{cm})$ do fêmur.

As análises de variância foram realizadas segundo o SAS Institute (1999). O experimento foi delineado em modelo fatorial, com 6 tratamentos (3 genótipos $\mathrm{x} 2$ idades de abate), e 15 replicatas, segundo o modelo matemático: $Y_{i j k}=\mu+G_{i}+A_{j}+(G G \times A A)_{i j}+e_{i j k}$ em que $Y_{\mathrm{ijk}}$ é o valor observado para cada característica analisada; $\mu$ é a média geral; $\mathrm{GG}_{\mathrm{i}}$ é o efeito do genótipo
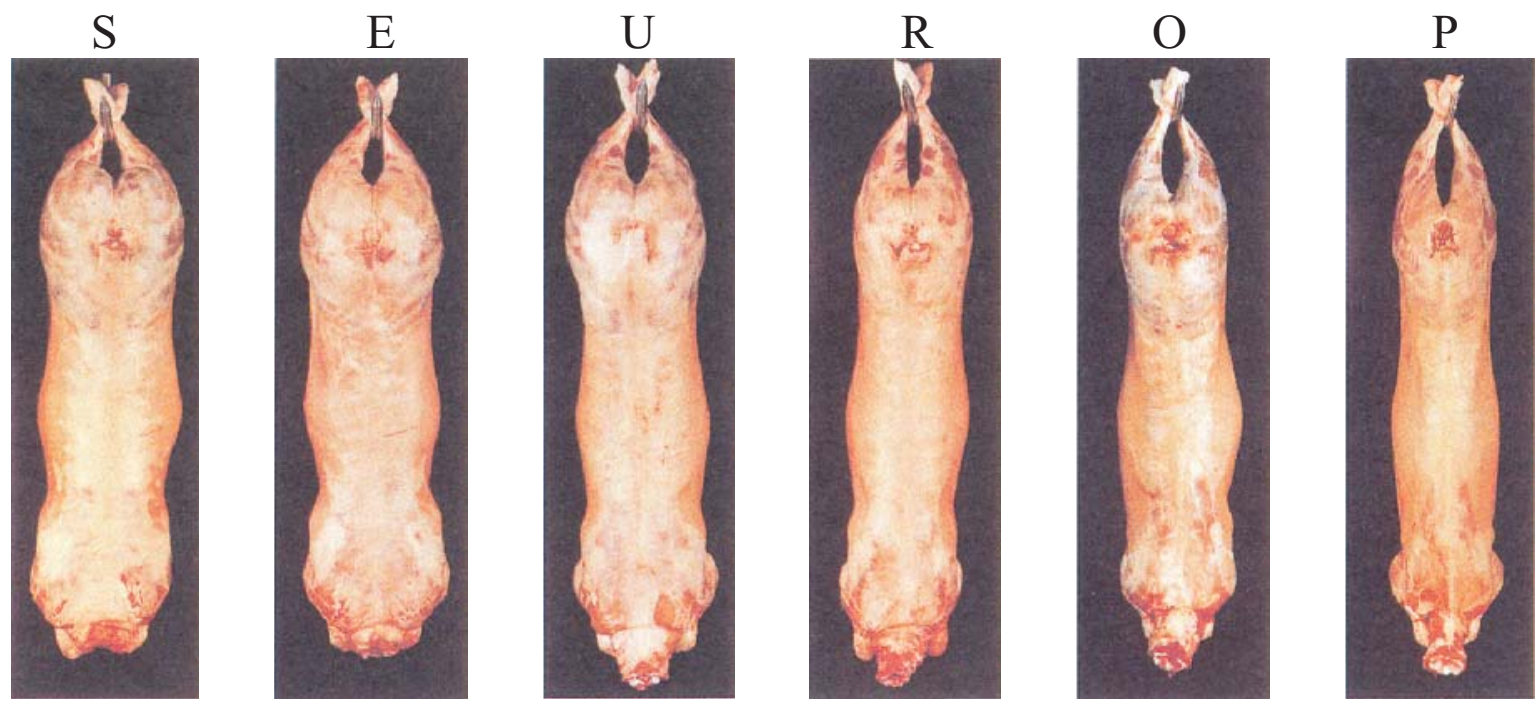

Figura 1. Classes de conformação de carcaças ovinas pelo sistema SEUROP, de acordo com Modelo... (1994). 
i = 1 a 3 (1: Romney; 2: East Friesian x (Finn x Texel); 3: Finn $x$ Poll Dorset); $\mathrm{AA}_{\mathrm{j}}$ é o efeito da idade ao abate $\mathrm{j}=1$ e 2 (1: 150 dias e 2: 300 dias); e é é orro do i-ésimo genótipo, j-ésima idade ao abate e k-ésima replicata $(\mathrm{k}=1 \ldots 15)$.

Para todas as características, exceto peso vivo e peso da carcaça, foram feitos ajustes estatísticos, de forma que genótipos e idades ao abate fossem comparados num mesmo peso médio de carcaça ou perna, tendo-se utilizado como covariáveis os pesos da carcaça e da perna.

Esses ajustes foram realizados, porque as características variaram de acordo com mudanças no peso da carcaça (Sañudo et al., 1996, 1998; Osório et al., 1998), e não seria possível identificar se as diferenças eram causadas por efeitos de grupos genéticos ou idades ao abate, ou se elas apenas refletiram as variações nos pesos das carcaças.

\section{Resultados e Discussão}

Os resultados das medidas realizadas no abate e na dissecação das pernas estão apresentados e discutidos, considerando-se os três genótipos e as duas idades ao abate. Não houve interação entre grupos genéticos e idades ao abate, para as características avaliadas.

Os comprimentos das carcaças, ajustados para peso, foram maiores nos grupos East Friesian x (Finn x Texel) e Finn x Dorset, em relação ao Romney, e as carcaças mais longas, provavelmente, refletiram o uso de raças paternas maiores (Tabela 2). Os valores de comprimento de carcaça, ajustados para peso, sugerem que o aumento de peso proporcional foi maior do que o aumento de peso total nos animais abatidos aos 300 dias e que passaram pelas estações de verão e outono, as quais, na
Nova Zelândia, são caracterizadas por condições adversas de clima e de vegetação, além de os animais do lote abatido, mais tardiamente, terem apresentado eczema facial, o que pode ter influenciado nos resultados.

As avaliações subjetivas de musculatura da carcaça, a um mesmo peso de carcaça, com menores valores que indicavam melhor musculatura, diferiram entre as idades de abate. As carcaças dos cordeiros, abatidos aos 150 dias de idade, apresentaram melhores conformações, em relação àquelas dos abatidos aos 300 dias.

Os resultados da Tabela 3 resumem o efeito do genótipo, na composição da perna dos cordeiros, em músculo, gordura e osso. O peso total dos músculos da perna foi maior para o grupo East Friesian x (Finn $\mathrm{x}$ Texel), em relação aos demais (1,8\% maior do que o do grupo Romney), entretanto essa diferença não foi consistente para os cinco músculos estudados. O maior peso dos músculos no grupo East Friesian x (Finn $\mathrm{x}$ Texel), a um mesmo peso de perna, não foi causado por menores pesos de osso e gordura, que não diferiram entre os grupos. Não houve diferenças nas gorduras subcutânea e intermuscular, assim como na relação gordura subcutânea:gordura intermuscular entre os genótipos.

A um mesmo peso de perna, o fêmur foi mais pesado para os grupos Romney e East Friesian x (Finn x Texel); além disso, o grupo Romney também apresentou ossos femorais mais curtos do que os dos demais grupos. Os resultados de outros estudos mostraram que várias medidas do tamanho do esqueleto, de carcaças ovinas mais compactas, estiveram associadas à pior conformação (Kirton et al., 1983; Kadim et al., 1989).

Relações músculo:osso maiores foram observadas nos grupos East Friesian x (Finn x Texel) e Finn x Dorset, em relação ao Romney, mas a musculosidade foi maior

Tabela 2. Efeito do genótipo e da idade ao abate, nas características da carcaça de $\operatorname{cordeiros}^{(1)}$.

\begin{tabular}{|c|c|c|c|c|c|}
\hline \multirow[t]{2}{*}{ Característica $^{(2)}$} & \multicolumn{3}{|c|}{ Genótipo $^{(3)}$} & \multicolumn{2}{|c|}{ Idade ao abate (dias) } \\
\hline & Rom & $\mathrm{EF} \times(\mathrm{Fn} x \mathrm{Tx})$ & Fn $x$ Ds & 150 & 300 \\
\hline$\overline{\text { Peso ao abate }(\mathrm{kg})}$ & 40,6 & 41,2 & 42,4 & $38,2 b$ & $44,7 \mathrm{a}$ \\
\hline Peso da carcaça $(\mathrm{kg})$ & $17,9 b$ & $18,2 \mathrm{ab}$ & $19,0 \mathrm{a}$ & $16,8 b$ & $19,9 a$ \\
\hline Comprimento de carcaça $(\mathrm{cm})$ & $100,9 b$ & $102,3 \mathrm{a}$ & $103,1 \mathrm{a}$ & $100,5 b$ & $103,7 \mathrm{a}$ \\
\hline Conformação ${ }^{(4)}$ & $3,0 \mathrm{~b}$ & $3,5 \mathrm{a}$ & $3,0 \mathrm{~b}$ & $3,0 \mathrm{~b}$ & $3,5 \mathrm{a}$ \\
\hline
\end{tabular}

(1)Médias seguidas de letras diferentes, na mesma linha, diferem pelo teste de Tukey a 5\% de probabilidade. ${ }^{(2)}$ Valores ajustados para mesmo peso de carcaça. ${ }^{(3)}$ Rom: Romney; Ef x (Fn x Tx): East Friesian x (Finn x Texel); Fn x Ds: Finn x Poll Dorset. ${ }^{(4)}$ Escala SEUROP de 6 pontos, onde 1 = muito musculoso (avaliação visual). 
nos grupos Romney e East Friesian x (Finn x Texel). Segundo Kempster et al. (1981), a conformação nem sempre mostra boa correlação com a relação músculo:osso, especialmente quando se comparam animais de raças diferentes. Kadim et al. (1989) indicaram que carcaças com maior musculosidade eram também menores.

Entre uma seleção de medidas objetivas de conformação de carcaça, o índice de musculosidade, baseado na espessura dos músculos ao redor do fêmur, em relação ao comprimento do fêmur, está ligado a escores subjetivos de musculatura ou de conformação de carcaças ovinas.

Ao comparar diferentes genótipos, Santos et al. (2002) constataram maior relação músculo:osso $(2,65)$ na raça Santa Inês, em relação à raça Bergamácia $(2,35)$. Tais valores foram inferiores aos deste estudo, em que a menor relação músculo:osso $(6,69)$ foi para cordeiros Romney. Neste trabalho, cordeiros mestiços East Friesian x (Finn x Texel) e Romney apresentaram maior índice de musculosidade, em relação aos mestiços Finn x Poll Dorset. Hopkins et al. (1997) também concluíram que cordeiros cruzados Texel apresentaram maior índice de musculosidade, em relação aos cruzados Poll Dorset. Kirton et al. (1997), ao comparar as progênies do cruzamento de 39 raças com ovelhas Romney, observaram que as oriundas de Texel e Poll
Dorset tiveram maiores proporções de músculo na perna, o que concorda com os resultados obtidos neste trabalho, em que cordeiros East Friesian x (Finn x Texel) apresentaram maior proporção de músculo, em relação aos da raça Romney.

Os cordeiros abatidos aos 300 dias mostraram maior peso de músculo, menor gordura da perna, relações músculo:osso semelhantes e menor musculosidade, do que os abatidos com 150 dias (Tabela 3). Esses resultados discordam dos obtidos por Sents et al. (1982), em que a gordura apresentou proporção crescente em carcaças mais pesadas, com diminuição das proporções de músculo e osso, em virtude de problemas climáticos e sanitários que, certamente, afetaram os animais abatidos mais tardiamente.

O maior peso de músculo ajustado, para mesmo peso de perna, foi associado com músculos semitendinosos mais pesados, entretanto, não ocorreram diferenças nos outros quatro músculos estudados. Fennessy et al. (1992) também encontraram efeitos da idade ao abate, nas variáveis de composição, e sugeriram que os efeitos não controlados do meio, dentre os quais parasitas e temperatura, podem afetar a composição da carcaça de ovinos criados em regime de pasto.

Tabela 3. Efeito do genótipo na composição e na musculosidade da perna de $\operatorname{cordeiros}^{(1)}$.

\begin{tabular}{|c|c|c|c|c|c|}
\hline \multirow[t]{2}{*}{ Característica $^{(2)}$} & \multicolumn{3}{|c|}{ Genótipo $^{(3)}$} & \multicolumn{2}{|c|}{ Idade ao abate (dias) } \\
\hline & Rom & Ef x (Fn x Tx $)$ & Fn $x$ Ds & 150 & 300 \\
\hline \multicolumn{6}{|l|}{ Músculo da perna $(\mathrm{g})$} \\
\hline Músculo total & $1.941 \mathrm{~b}$ & $1.975 \mathrm{a}$ & $1.955 \mathrm{ab}$ & $1.933 \mathrm{~b}$ & $1.981 \mathrm{a}$ \\
\hline Semimembranoso & 243 & 249 & 251 & 246 & 249 \\
\hline Semitendinoso & 94 & 96 & 96 & $93 b$ & $98 \mathrm{a}$ \\
\hline Bíceps femoral & $254 \mathrm{~b}$ & $269 \mathrm{a}$ & $267 \mathrm{a}$ & 264 & 263 \\
\hline Quadríceps femoral & 382 & 385 & 370 & 382 & 376 \\
\hline Adutor & $108 b$ & $118 \mathrm{a}$ & $118 \mathrm{a}$ & 113 & 116 \\
\hline \multicolumn{6}{|l|}{ Gordura da perna (g) } \\
\hline Gordura total & 332 & 306 & 332 & $348 \mathrm{a}$ & $302 b$ \\
\hline Gordura subcutânea & 192 & 173 & 192 & $213 a$ & $162 b$ \\
\hline Gordura intermuscular & 141 & 134 & 141 & 135 & 139 \\
\hline \multicolumn{6}{|l|}{ Ossos da perna $(\mathrm{g})$} \\
\hline Osso total & 496 & 489 & 481 & 487 & 491 \\
\hline Fêmur & $161 \mathrm{a}$ & $160 \mathrm{a}$ & $154 \mathrm{~b}$ & $156 b$ & $161 \mathrm{a}$ \\
\hline Comprimento do fêmur $(\mathrm{cm})$ & $17,30 \mathrm{~b}$ & $17,60 \mathrm{a}$ & $17,80 \mathrm{a}$ & $17,10 \mathrm{~b}$ & $18,00 \mathrm{a}$ \\
\hline Relação músculo:osso ${ }^{(4)}$ & $6,69 \mathrm{~b}$ & $7,00 \mathrm{a}$ & $7,17 \mathrm{a}$ & 7,06 & 6,84 \\
\hline Musculosidade & $0,456 \mathrm{a}$ & $0,453 \mathrm{a}$ & $0,441 \mathrm{~b}$ & $0,466 \mathrm{a}$ & $0,434 \mathrm{~b}$ \\
\hline
\end{tabular}

(1)Médias seguidas de letras diferentes, na mesma linha, diferem pelo teste de Tukey a 5\% de probabilidade. (2)Valores ajustados para mesmo peso de perna limpa. ${ }^{(3)}$ Rom: Romney; Ef x (Fn x Tx): East Friesian x (Finn x Texel); Fn x Ds: Finn x Poll Dorset. (4)Relação entre o peso de cinco músculos (bíceps femoral, semimembranoso, semitendinoso, quadríceps femoral e adutor) e o peso do fêmur. 


\section{Conclusões}

1. As carcaças dos cordeiros provenientes de pais East Friesian x (Finn x Texel) têm maior relação músculo:osso, em relação às do grupo Romney.

2. As características músculo:osso e musculosidade nem sempre variam de modo paralelo, e devem, portanto, ser avaliadas conjuntamente.

\section{Referências}

ANOUS, M.R. Relationship between muscle and bone development of the hind limbs of different breeds. Animal Production, v.48, p.121-129, 1989.

BROWN, A.J.; WILLIAMS, D.R. Sheep carcass evaluation: measurement of composition using a standardized butchery method. Langford: Agricultural Research Council; Meat Research Council, 1979. 16p. (Memorandum, 38).

CLARKE, J.N.; JOHNSON, D.L.; BENNETT, G.L.; KIRTON, A.H.; RAE, A.L. Genetic variation and relationships among carcass traits of lambs. Ruakura: Animal Research Station Genetic Section Annual Report, 1984. p.32-33.

DeBOER, H.; DUMONT, B.L.; POMEROY, R.W.; WENIGER, T.H. Manual on E.A.A.P. reference methods for the assessment of carcass characteristics in cattle. Livestock Production Science, v.1, p.151-164, 1974.

DUMONT, B.L.; POULIQUEN, O. Morphological traits of femur and tibia in relation to fleshiness (muscle/bone ratio) in lambs. In: WORLD CONGRESS ON SHEEP AND CATTLE BREEDING, 3., 1988, Paris. Proceedings. Paris: INRA, 1988. p.477-479.

FENNESSY, P.F.; BAIN, W.E.; GREER, G.J.; JOHNSTONE, P.D. Carcass characteristics of progeny from ram lambs selected for high or low ultrasonic backfat thickness. New Zealand Journal of Agricultural Research, v.35, p.177-183, 1992.

HOPKINS, D.L.; FOGARTY, N.M.; MENZIES, D.J. Differences in composition, muscularity, muscle: bone ratio and cut dimensions between six lamb genotypes. Meat Science, v.45, p.439-450, 1997.

KADIM, I.T.; PURCHAS, R.W.; RAE, A.L.; BARTON, R.A. Carcass characteristics of southdown rams from high and low backfat selection lines. New Zealand Journal of Agricultural Research, v.32, p.181-191, 1989.

KEMPSTER, A.J.; CROSTON, D.; JONES, D.W. Value of conformation as an indicator of sheep carcass composition within and between breeds. Animal Production, v.33, p.39-49, 1981.

KEMPSTER, A.J.; CUTHBERTSON, A.; HARRINGTON, G. Carcase evaluation in livestock breeding, production and marketing. London: Granada, 1982.
KIRTON, A.H.; DUGANZICH, D.M.; MERCER, G.J.K.; CLARK, J.N.; DOBBIE, J.L.; WILSON, J.A. Muscle distribution in lamb progeny from several breeds. Proceedings of the New Zealand Society of Animal Production, v.57, p.267-270, 1997.

KIRTON, A.H.; WOOD, E.G.; DUGANZICH, D.M. Comparison of well and poorly muscled lamb carcasses as selected by experienced meat industry personnel. Proceedings of the New Zealand Society of Animal Production, v.43, p.111-113, 1983.

MODELO comunitario de clasificación de canales de ovinos. Luxemburgo: Oficina de Publicaciones Oficiales de las Comunidades Europeas, 1994. (Folleto n. CM-84-94-694-ES-D).

NSOSO, J.S.; YOUNG, M.J.; BEATSON, P.R. A review of carcass conformation in sheep: assessment, genetic control and development. Small Ruminant Research, v.35, p.89-96, 2000.

OSÓRIO, J.C.S.; MARIA, G.; JARDIM, P.O.; FARIA, H.V.; PIMENTEL, M.A. Caracteres de crecimiento, sacrificio y canal en corderos de raza Corriedale criados en un sistema sostenible sobre pastos naturales de Rio Grande do Sul (Brasil). Información Técnica Económica Agraria, v.94, p. 63-73, 1998.

OSÓRIO, J.C.S.; OLIVEIRA, N.M.; NUNES, A.P.; POUEY, J.L. Produção de carne em ovinos de cinco genótipos. 3. Perdas e morfologia. Ciência Rural, v.26, p.477-481, 1996.

PURCHAS, R.W. An assessment of the role of ph differences in determining the relative tenderness of meat from bulls and steers. Meat Science, v.27, p.129-140, 1990.

PURCHAS, R.W.; DAVIES, A.S.; ABDULLAH, A.Y. An objective measure of muscularity: changes with animal growth and differences between genetic lines of southdown sheep. Meat Science, v.30, p.81-94, 1991.

SANTOS, L.E.; BUENO, M.S.; CUNHA, E.A.; LEMOS NETO, M.J. Desempenho e características de carcaça de cordeiros Santa Inês e cruzados com raças especializadas para corte. 2002. Disponível em: <http://www.ovinosbrasil.com>. Acesso em: 6 set. 2003.

SAÑUDO, C.; SANCHEZ, A.; ALFONSO, M. Small ruminant production systems and factors affecting lamb meat quality. Meat Science, v.49, p.529-564, 1998.

SAÑUDO, C.; SANTOLARIA, M.P.; OSÓRIO, M.T.M.; SIERRA, I. Influence of carcass weight on instrumental and sensory lamb meat quality in intensive production systems. Meat Science, v.42, p.195-202, 1996.

SAS INSTITUTE (Cary, Estados Unidos). SAS/STAT user's guide. Cary, North Caroline, 1999.

SENTS, A.E.; WALTER, L.E.; WHITEMAN, J.V. Performance and carcass characteristics of ram lambs slaughtered at different weights. Journal of Animal Science, v.55, p.1360-1369, 1982.

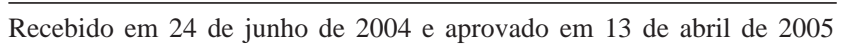

